\title{
Caregiver Evaluation of the Quality of End-Of-Life Care (CEQUEL) Scale: The Caregiver's Perception of Patient Care Near Death
}

\author{
Philip C. Higgins ${ }^{1,2,3}$, Holly G. Prigerson ${ }^{3,4,5,6 *}$ \\ 1 Doctoral candidate, Boston College Graduate School of Social Work, Chestnut Hill, Massachusetts, United States of America, 2 Department of Psychosocial Oncology and \\ Palliative Care, Dana-Farber Cancer Institute, Boston, Massachusetts, United States of America, 3 Center for Psychosocial Epidemiology and Outcomes Research, Dana- \\ Farber Cancer Institute, Boston, Massachusetts, United States of America, 4 Division of Population Sciences, Department of Medical Oncology, Dana-Farber Cancer \\ Institute, Boston, Massachusetts, United States of America, 5 Department of Psychiatry, Brigham and Women's Hospital, Boston, Massachusetts, United States of America, \\ 6 Harvard Medical School, Boston, Massachusetts, United States of America
}

\begin{abstract}
Purpose: End-of-life (EOL) measures are limited in capturing caregiver assessment of the quality of EOL care. Because none include caregiver perception of patient suffering or prolongation of death, we sought to develop and validate the Caregiver Evaluation of Quality of End-of-Life Care (CEQUEL) scale to include these dimensions of caregiver-perceived quality of EOL care.

Patients and Methods: Data were derived from Coping with Cancer $(\mathrm{CwC})$, a multisite, prospective, longitudinal study of advanced cancer patients and their caregivers ( $\mathrm{N}=275$ dyads). Caregivers were assessed before and after patient deaths. CEQUEL's factor structure was examined; reliability was evaluated using Cronbach's $\alpha$, and convergent validity by the strength of associations between CEQUEL scores and key EOL outcomes.

Results: Factor analysis revealed four distinct factors: Prolongation of Death, Perceived Suffering, Shared Decision-Making, and Preparation for the Death. Each item loaded strongly on only a single factor. The 13-item CEQUEL and its subscales showed moderate to acceptable Cronbach's $\alpha$ (range: $0.52-0.78$ ). 53\% of caregivers reported patients suffering more than expected. Higher CEQUEL scores were positively associated with therapeutic alliance $(\rho=.13 ; p \leq .05)$ and hospice enrollment $(z=-2.09 ; p \leq .05)$, and negatively associated with bereaved caregiver regret $(\rho=-.36, p \leq .001)$ and a diagnosis of Posttraumatic Stress Disorder $(z=-2.06 ; p \leq .05)$.

Conclusion: CEQUEL is a brief, valid measure of quality of EOL care from the caregiver's perspective. It is the first scale to include perceived suffering and prolongation of death. If validated in future work, it may prove a useful quality indicator for the delivery of EOL care and a risk indicator for poor bereavement adjustment.
\end{abstract}

Citation: Higgins PC, Prigerson HG (2013) Caregiver Evaluation of the Quality of End-Of-Life Care (CEQUEL) Scale: The Caregiver's Perception of Patient Care Nea Death. PLoS ONE 8(6): e66066. doi:10.1371/journal.pone.0066066

Editor: Wendy Wing Tak Lam, The University of Hong Kong, Hong Kong

Received February 20, 2013; Accepted May 2, 2013; Published June 6, 2013

Copyright: (c) 2013 Higgins, Prigerson. This is an open-access article distributed under the terms of the Creative Commons Attribution License, which permits unrestricted use, distribution, and reproduction in any medium, provided the original author and source are credited.

Funding: This research was supported in part by the following grants to PCH: DSW1009403SW from the American Cancer Society; and to HGP: MH63892 from the National Institute of Mental Health and CA106370 and CA156732 from the National Cancer Institute; and the Center for Psychosocial Epidemiology and Outcomes Research, Dana-Farber Cancer Institute. The funders had no role in study design, data collection and analysis, decision to publish, or preparation of the manuscript.

Competing Interests: The authors have declared that no competing interests exist.

*E-mail: holly_prigerson@dfci.harvard.edu

\section{Introduction}

Cancer caregivers are key stakeholders not only in active cancer care, but also in terminal care and bereavement. Caregivers provide an important perspective on, and reliable assessment of, the quality of end-of-life (EOL) care patients receive [1]. Caregiver ratings of the quality of EOL care may also have consequences for their mental health, proving a risk factor for poor bereavement adjustment.

Many have studied what it means to have a 'good death' [2], the distinctions between quality of life (QOL) and quality of death [3], and how best to measure the quality of care received at the EOL [4]-[7]. Research has identified factors important to dying patients and their caregivers, including avoidance of prolonged death or suffering, shared decision-making, communication with providers about patient wishes, awareness of prognosis and preparation for death [8]-[15]. Instruments designed to measure the quality of EOL care [16] usually elicit patient experiences via patient or proxy response, rather than the caregiver's experience [11], [17][20]. How caregivers perceive a dying loved one's care should be of concern to healthcare providers, as it is an indicator of the quality of care the team has provided and also affects caregiver bereavement [21]-[33]. Existing caregiver measures typically assess caregiver burden or QOL, but not perceived quality of care to the dying patient [34] 
A key exception is the Toolkit After-Death Bereaved Family Member Interview, which measures multiple domains of caregiver-perceived quality of care in the final week of life [35]. Although the Toolkit is a broad and clinically relevant instrument that offers the best current means by which to measure caregiver evaluation of EOL care, it omits two factors identified as important to dying patients and their caregivers: perceived patient suffering and prolongation of death [8]-[15]. The Toolkit assesses perceived adequacy of symptom management, but not the meaning caregivers derive from inadequate palliation. This perceived suffering or violent harm to the patient may greatly influence caregivers' bereavement adjustment. Similarly, the Toolkit does not capture the caregiver's experience of 'emotional limbo' during the seemingly indefinite period of waiting for death to come. Caregivers often feel that better EOL care could have curtailed this waiting period. Bereaved caregivers report wishing that they had been better prepared for the dying process - including how long it might take - by the care team [30], [31], [36]. As our understanding of death and dying grows, there is heightened recognition of the multiple dimensions involved in caregiver evaluation of the quality of EOL care. We consider perceived suffering and prolongation of death to be two such important dimensions, the inclusion of which extends the important work of the Toolkit's authors to create a more comprehensive measure.

This study's purpose was to develop and validate the Caregiver Evaluation of Quality of End of Life Care (CEQUEL) scale, a novel measure of perceived quality of EOL care that incorporates key Toolkit components with new measures of perceived suffering and prolongation of death. Caregiver data collected in the Coping with Cancer $(\mathrm{CwCl})$ study were used to select relevant items for assessing the quality of EOL care, which were then analyzed to isolate core GEQUEL components and to determine CEQUEL's reliability and validity.

\section{Patients and Methods}

\section{Ethics statement}

Prior to the research being conducted, approval was obtained from the human subjects committees of all seven participating centers: Dana-Farber Cancer Institute (Boston, MA); Massachusetts General Hospital (Boston, MA); New Hampshire Oncology Hematology (Hookset, NH); Parkland Hospital (Dallas, TX); Simmons Comprehensive Cancer Center (Dallas, TX); Veterans' Affairs Connecticut Comprehensive Cancer Clinics (West Haven, CT); and Yale University Cancer Center (New Haven, CT). All participants provided written informed consent. Dr. Prigerson had full access to all of the data in the study and takes responsibility for the integrity of the data and the accuracy of the data analysis.

\section{Study design and sample}

Coping with Cancer (CwC1) was an NCI- and NIMH-funded prospective, longitudinal, multi-site study of terminally ill cancer patients and their informal caregivers (e.g., spouse or adult child) followed through bereavement. Patients were recruited from September 1, 2002 to February 28, 2008 from seven outpatient sites in Texas, New York and New England. Approval was obtained from the human subjects committees of all participating centers; all enrolled patients provided written informed consent and received $\$ 25$.

CwC1 patient eligibility criteria included an advanced metastatic cancer diagnosis, disease progression through chemotherapy, age $\geq 20$ years, presence of an informal caregiver, absence of significant cognitive impairment, and English or Spanish proficiency. Eligible caregivers provided the majority of patients' unpaid, informal care. Research staff identified participants from weekly clinic rosters. Patients and caregivers were interviewed separately at baseline (Wave 1), and caregivers were interviewed again following patients' deaths (Wave 2). Additional information was obtained via chart review and post-mortem interviews with designated primary caregivers $(\mathrm{N}=148 ; 57 \%)$ or with healthcare providers or others caring for patients at the time of death ( $\mathrm{N}=114 ; 43 \%)$.

The present report focuses on 275 patient/caregiver dyads with complete data for thirteen items used in the final model (initial sample $=315$ ). Forty dyads with missing CEQUEL data did not differ significantly from those with full data on all examined demographic characteristics other than relationship to the patient (those identifying as "friend" were more likely to have missing information).

The median time from Wave 1 interview to death for the final analyzed cohort was three months, and from death to Wave 2 interview was 6.5 months.

\section{Scale development}

The authors reviewed over $400 \mathrm{CwCl}$ Wave 2 items, identifying 69 related to caregiver perception of quality of EOL care. Item identification was based on relevant literature [8]-[15] as well as the authors' clinical judgment and research experience in psycho-oncology, EOL care, bereavement, and psychometrics. The item pool was further reduced to 21 by discarding redundant items, those related to patient care beyond the final week of life (so that all had the same time reference) and those inquiring about specific symptoms (for greater generalizability). Ten items were yes/no questions, and eleven were Likert scale questions. In order to achieve more balanced item distributions we dichotomized 4and 10-point Likert items at midpoint and 7-point items using 4 as the split point (i.e. $1-4=1,5-7=2$ ). We reversed and/or recoded items as necessary to facilitate meaningful item summation, with " 1 " signifying perceived poorer quality of care and " 2 " perceived better quality of care.

\section{Caregiver demographics}

Caregivers answered questions at Wave 1 about their own gender, age, race/ethnicity, marital status, income, education, religion and relationship to the patient.

\section{Items included in the factor analysis}

The initial 21 items retained for factor analysis were all assessed in the Wave 2 bereaved caregiver interview. Twelve were adapted from the Toolkit, one from the Needs Near the End of Life Screening Tool (NEST) [37], and eight originated with CwC1.

\section{Correlates and outcomes}

Select Wave 1, post-mortem and Wave 2 items were retained for convergent validity analysis [38], based on the hypothesis that all items would be significantly associated with CEQUEL scores.

Wave 1 patient items included patient baseline reports of advance care planning and EOL discussions with their physicians. In previous CwC1 studies, patient-provider discussion of EOL wishes was associated with less aggressive medical care, which was then associated with improved QOL in bereaved caregivers. Also retained were Wave 1 caregiver responses on the 14-item Brief RCOPE, a validated measure of positive and negative religious coping [39]. Negative religious coping has been associated with increased caregiver burden, poor mental health, and decreased QOL and satisfaction [40], [41]. Finally, patients answered Wave 1 questions about the degree to which they trusted and respected 
their physician, felt respected and "seen as a whole person" by their physician, and felt comfortable asking their physician questions about their care. Responses to these items were summed as a measure of "therapeutic alliance", which has been previously identified as important to the QOL of dying patients and their families [1], [12].

Post-mortem items inquired about place of death, hospice enrollment, intensive care unit (ICU) admission and resuscitation. Prior research suggests that less aggressive medical care, dying on home hospice rather than in an ICU, and longer hospice enrollment are associated with better caregiver satisfaction with care, QOL and mental health [1], [10], [16]-[][18], [42], [43].

Wave 2 caregiver items included questions related to caregiver regret, which has been inversely associated with perception of peaceful death [44]. Additional Wave 2 items were included to capture psychosocial distress in bereavement as an expected outcome of poor EOL care [33]. These include items from the Yale Evaluation of Suicidality (YES) scale [45], [46], the Stressful Caregiving Adult Response to Experience of Dying (SCARED) scale [47], the Beck Hopelessness Scale (BHS) [48], and the Structured Clinical Interview for DSM-IV (SCID) Axis I modules [49], [50].

\section{Statistical analyses}

Descriptive statistics, means-difference testing, and correlational analyses were performed using SPSS Statistics, Version 19.0 (SPSS, Inc., 1989-2010). Analysis of the 21-item correlation matrix was conducted via exploratory factor analysis (EFA) techniques, using Mplus, Version 6.12 (Muthén \& Muthén, 1998-2011). As suggested by Muthén et al. [51] for factor analysis with binary outcomes, a weighted least squares extraction method using tetrachoric correlations was employed. Item and factor retention was based on Muthén [52] criteria including Eigenvalues $>1$ [53], scree plot analysis [54], no negative residual variances, factor loading patterns, and substantive and theoretical interpretability. Parallel analysis [55] confirmed the appropriate number of factors. Model fit statistics were interpreted following Yu's [56] recommendations.

Items with factor loadings $<0.4$ were removed in successive factor analyses. Consecutive analyses were conducted until a 4factor solution with clear factor loadings and good model fit was achieved. Final factor analysis items were summed and internal consistency was evaluated using Cronbach's $\alpha$ [57]. The nonnormal distribution of CEQUEL scores required the use of nonparametric tests to evaluate demographic differences in CEQUEL scores as well as associations between CEQUEL scores and related EOL indicators.

\section{Results}

\section{Sample}

Table 1 provides relevant characteristics for the 275 caregivers used in this report. $76 \%$ were female, $70 \%$ were white, $68 \%$ were married, and 39\% were Catholic. Caregivers ranged in age from 20 to 83 years $($ Mean $=51.9$, Median $=53) .53 \%$ were the spouse or partner of the patient. $58 \%$ of caregivers in the present study were recruited from community-based sites. Mean CEQUEL scores were significantly lower (indicating poorer perceived quality of care) for Catholic than for non-Catholic caregivers (23.2 vs. $23.9, p=0.015)$, as well as for caregivers reporting no religious affiliation compared to those with a religious affiliation (22.1 vs. 23.8, $\mathrm{p}=0.021)$. Pentecostalists scored highest (Mean $=24.5)$, followed by Baptists (Mean = 24.3). CEQUEL scores did not vary significantly by other caregiver characteristics, but they did vary by recruitment site, with mean CEQUEL scores significantly lower for Yale caregivers than for those at both Simmons (22.8 vs. 24.5, $\mathrm{p}=0.003)$ and Parkland (22.8 vs. 24.1, $\mathrm{p}=0.001)$. This site difference remained significant at $\mathrm{p}<0.05$ after controlling for religion as well as race.

\section{Factor analysis}

Eigenvalue, scree-plot and parallel analyses all favored a 4factor structure. Eight items with factor loadings $<0.4$ or with negative residual variances were dropped from successive models. Importantly, four of these were Toolkit items related to individualfocused care (e.g. patient being treated with respect and kindness). One item ("Was there any medical procedure or treatment that happened to patient that was inconsistent with his/her previously stated wishes?") with a 0.39 factor loading was retained because its removal created model instability and because retention made substantive sense. Figure 1 shows the scree plot suggesting four factors for the final model, each with an Eigenvalue greater than 1.

Twelve of thirteen items loaded significantly on one of four identified factors (Table 2): Prolongation of Death ("Prolongation"), Perceived Suffering ("Suffering"), "Shared Decision-Making" and Preparation for the Death ("Preparation"). Toolkit items all loaded on Shared Decision-Making or Preparation, whereas CwC1-specific items all loaded on Prolongation or Suffering. Small, positive, significant correlations between most factors indicated that they represent four distinct aspects of a single construct. Fit statistics indicated good model fit.

\section{Psychometric properties of the CEQUEL scale}

CEQUEL scores ranged from 16 to 26 out of a possible 26 points $(M=23.6, \mathrm{SD}=2.2$, Median =24), with higher scores signifying better perceived quality of care. One item - "How much did patient suffer compared to what you expected?" - had a slight majority reporting poorer perceived quality of care.

\section{Reliability}

CEQUEL demonstrated an acceptable Cronbach's $\alpha$ of 0.69 . Prolongation and Suffering had acceptable $\alpha$ 's of 0.78 and 0.73 , while Shared Decision-Making and Preparation had moderate $\alpha$ 's of 0.52 and 0.54 .

\section{Convergent validity}

Table 3 illustrates patterns of association between CEQUEL and subscale scores and related EOL outcomes. In interpreting these associations, it is important to recall that higher CEQUEL and subscale scores reflect better perceived quality of care. Higher Prolongation and Suffering scores actually reflect lower levels of perceived prolongation and suffering (hence better quality of care within these domains).

Wave 1 patient items. Higher Suffering scores (indicating less perceived suffering) were positively associated with baseline completion of a DNR order $(\mathrm{p} \leq .05)$. There were no other significant differences in CEQUEL or subscale scores based on baseline advance care planning. Higher CEQUEL scores were significantly positively associated with therapeutic alliance $(\mathrm{p} \leq .05)$.

Wave 1 caregiver items. Higher Preparation scores were significantly associated with higher levels of positive religious coping $(\mathrm{p} \leq .05)$ and higher Prolongation and Suffering scores (i.e. less perceived prolongation and suffering) were associated with lower levels of negative religious coping $(\mathrm{p} \leq .05)$.

Post-mortem items. There were no significant differences in CEQUEL or subscale scores based on location of death, ICU admission, resuscitation or receipt of inpatient hospice care. 
Table 1. Demographic Characteristics of Sample Caregivers $(N=275)$.

\begin{tabular}{|c|c|c|c|}
\hline Characteristic & No. caregivers & & $\%$ \\
\hline \multicolumn{4}{|l|}{$\operatorname{Sex}^{\mathrm{a}}$} \\
\hline Male & 64 & & 24 \\
\hline Female & 201 & & 76 \\
\hline \multicolumn{4}{|l|}{ Age, years ${ }^{a}$} \\
\hline Mean & & 51.9 & \\
\hline SD & & 13.6 & \\
\hline \multicolumn{4}{|l|}{ Race/ethnicity ${ }^{\text {b }}$} \\
\hline White & 185 & & 70 \\
\hline Black & 37 & & 14 \\
\hline Asian-American, Pacific Islander, Indian & 5 & & 2 \\
\hline Hispanic & 33 & & 12.5 \\
\hline Other & 4 & & 1.5 \\
\hline \multicolumn{4}{|l|}{ Marital status ${ }^{c}$} \\
\hline Married & 172 & & 68 \\
\hline \multicolumn{4}{|l|}{ Income $^{d}$} \\
\hline$<\$ 31,000$ & 62 & & 25 \\
\hline$\geq \$ 31,000$ & 123 & & 50 \\
\hline Don't know & 45 & & 18 \\
\hline Declined & 14 & & 6 \\
\hline \multicolumn{4}{|l|}{ Education, years ${ }^{\mathrm{b}}$} \\
\hline Mean & & 13.5 & \\
\hline SD & & 3.6 & \\
\hline \multicolumn{4}{|l|}{ Religion $^{\mathrm{b}}$} \\
\hline Catholic & 102 & & 39 \\
\hline Protestant & 47 & & 18 \\
\hline Baptist & 36 & & 14 \\
\hline Pentecostal & 11 & & 4 \\
\hline Jewish & 13 & & 5 \\
\hline Other & 37 & & 14 \\
\hline None & 18 & & 7 \\
\hline \multicolumn{4}{|l|}{ Relationship to patient ${ }^{\mathrm{e}}$} \\
\hline Spouse/partner & 120 & & 53 \\
\hline Son/daughter & 57 & & 25 \\
\hline Sibling & 15 & & 7 \\
\hline Other relative & 17 & & 7 \\
\hline Friend & 6 & & 2 \\
\hline Parent & 11 & & 5 \\
\hline Other & 2 & & 1 \\
\hline \multicolumn{4}{|l|}{ Recruitment site $^{f}$} \\
\hline Yale University Cancer Center & 65 & & 24 \\
\hline Veterans' Affairs Connecticut Comprehensive Cancer Clinics & 13 & & 5 \\
\hline Memorial Sloan-Kettering Cancer Center & 18 & & 6.5 \\
\hline Simmons Comprehensive Cancer Center & 21 & & 7.5 \\
\hline Parkland Hospital & 89 & & 33 \\
\hline Dana-Farber Cancer Institute & 8 & & 3 \\
\hline Massachusetts General Hospital & 1 & & 0.5 \\
\hline New Hampshire Oncology Hematology & 56 & & 20.5 \\
\hline
\end{tabular}

Missing data: a: $N=265, b: N=264, c: N=253, d: N=244$, e: $N=228, f: N=271$.

doi:10.1371/journal.pone.0066066.t001 


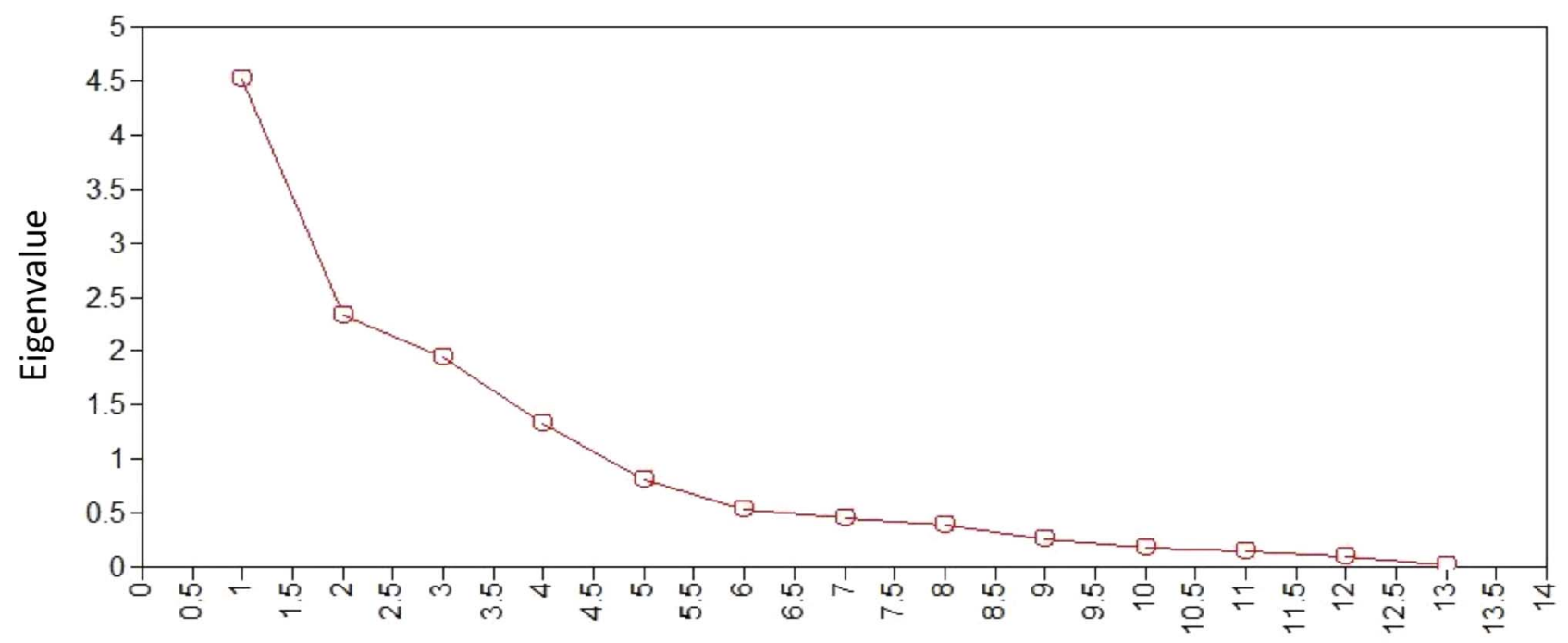

Factor number

Figure 1. Scree plot of final four-factor, thirteen-item model.

doi:10.1371/journal.pone.0066066.g001

Table 2. Factor Loading Scores and Fit Statistics for Final EFA Model.

\begin{tabular}{|c|c|c|c|c|c|}
\hline & $\begin{array}{l}\text { PROLONGATION } \\
\text { OF DEATH }\end{array}$ & $\begin{array}{l}\text { PERCEIVED } \\
\text { SUFFERING }\end{array}$ & $\begin{array}{l}\text { SHARED } \\
\text { DECISION- } \\
\text { MAKING }\end{array}$ & $\begin{array}{l}\text { PREPARATION } \\
\text { FOR THE } \\
\text { DEATH }\end{array}$ & \\
\hline $\begin{array}{l}\text { 1. Was the life of [PATIENT] prolonged by medical } \\
\text { interventions longer than you would have wished? }\end{array}$ & $0.848^{*}$ & & & & \\
\hline $\begin{array}{l}\text { 2. Was the life of [PATIENT] prolonged by medical interventions } \\
\text { when was, to the best of your knowledge, dying? }\end{array}$ & $0.990^{*}$ & & & & \\
\hline $\begin{array}{l}\text { 3. Was the life of [PATIENT] prolonged by medical interventions } \\
\text { that resulted in an increase of his/her suffering? }\end{array}$ & $0.843^{*}$ & & & & \\
\hline 4. How peaceful or violent did ___ 's death seem to you? & & $0.708^{*}$ & & & \\
\hline 5. To what extent do you think ___ suffered in dying? & & $0.953^{*}$ & & & \\
\hline $\begin{array}{l}\text { 6. How much did ___ suffer compared to what } \\
\text { you expected? }\end{array}$ & & $0.846^{*}$ & & & \\
\hline $\begin{array}{l}\text { 7. Was there ever a problem understanding what any doctor } \\
\text { was saying to you about what to expect from treatment? }\end{array}$ & & & $0.698^{*}$ & & \\
\hline $\begin{array}{l}\text { 8. Did you feel that the doctors you talked to listened to your } \\
\text { concerns about [PATIENT'S] medical treatment? }{ }^{\ddagger}\end{array}$ & & & $0.881^{*}$ & & \\
\hline $\begin{array}{l}\text { 9. Was there any medical procedure or treatment that } \\
\text { happened to (him/her) that was inconsistent with (his/her) } \\
\text { previously stated wishes? } ?^{\ddagger}\end{array}$ & & & 0.390 & & \\
\hline $\begin{array}{l}\text { 10. To the best of your knowledge, did [PATIENT'S] doctor } \\
\text { or the medical staff who cared for (him/her) speak to (him/her) } \\
\text { or you about (his/her) wishes about medical treatment? }{ }^{\ddagger}\end{array}$ & & & $0.548^{*}$ & & \\
\hline $\begin{array}{l}\text { 11. How often were you or other family members kept } \\
\text { informed about [PATIENT'S] condition } ?^{\ddagger}\end{array}$ & & & $(0.486)$ & $0.562^{*}$ & \\
\hline $\begin{array}{l}\text { 12. Did you or your family receive any information about } \\
\text { what to expect while (he/she) was dying? }{ }^{\ddagger}\end{array}$ & & & & $0.668^{*}$ & \\
\hline \multirow{2}{*}{$\begin{array}{l}\text { 13. At any time did you or your family receive any } \\
\text { information about the medicines that would be used to } \\
\text { manage (his/her) pain, shortness of breath, or other symptoms? }\end{array}$} & & & & $0.799^{*}$ & \\
\hline & CFI & TLI & RMSEA & RMSR & $x^{2}$ \\
\hline EFA fit statistics & 1.000 & 1.016 & 0.000 & 0.042 & $26.227(p=0.75)$ \\
\hline
\end{tabular}

${ }^{*} \mathrm{p} \leq .05$.

${ }^{\ddagger}$ Toolkit After-Death Bereaved Family Member Interview.

doi:10.1371/journal.pone.0066066.t002 


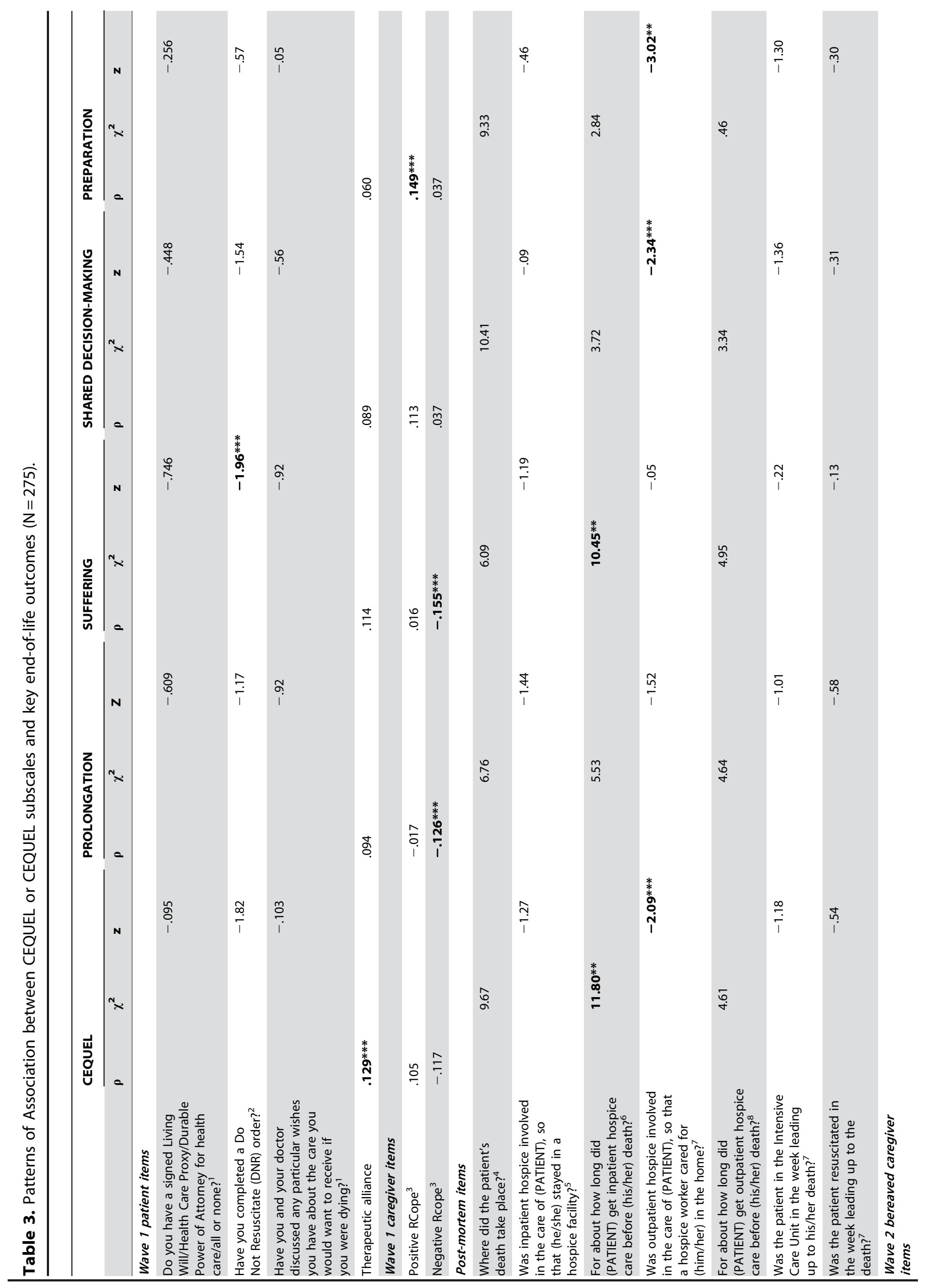




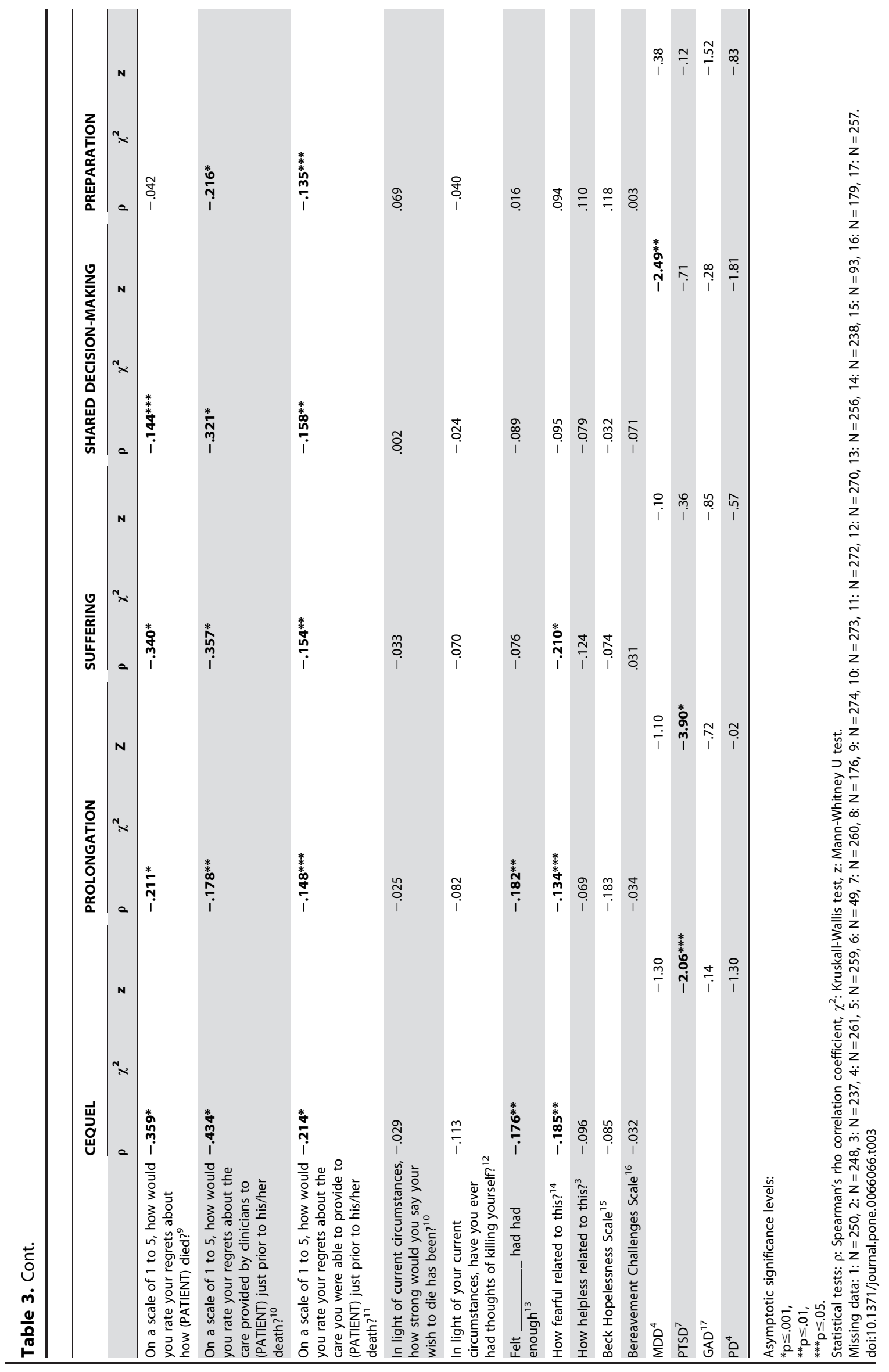


Higher CEQUEL and Suffering scores were positively associated $(\mathrm{p} \leq .01)$ with length of inpatient hospice enrollment. Higher CEQUEL $(\mathrm{p} \leq .05)$, Shared Decision-Making $(\mathrm{p} \leq .05)$ and Preparation $(\mathrm{p} \leq .01)$ scores were positively associated with receipt of home hospice care, but not length of enrollment.

Wave 2 bereaved caregiver items. Higher CEQUEL and subscale scores were negatively associated with regret. Higher CEQUEL and Prolongation scores were negatively associated with feeling that the patient had had enough $(\mathrm{p} \leq .01)$ and related fear. Finally, higher Shared Decision-Making scores were negatively associated with meeting criteria for Major Depressive Disorder $(\mathrm{p} \leq .01)$, and higher CEQUEL $(\mathrm{p} \leq .05)$ and Prolongation $(\mathrm{p} \leq .001)$ scores were negatively associated with meeting criteria for Posttraumatic Stress Disorder.

\section{Discussion}

The present analysis suggests that CEQUEL is a valid measure of quality of care at the EOL from the perspective of cancer patient caregivers. CEQUEL's thirteen items comprise four distinct but related factors that are consistent with both the literature and clinical practice related to EOL care: Prolongation of Death, Perceived Suffering, Shared Decision-Making, and Preparation for the Death. Perceived or actual inadequacy within any of these domains is associated with heightened caregiver risk for poor bereavement outcomes, but existing measurement tools do not capture caregiver perceptions of suffering and prolongation of death. Their inclusion in CEQUEL, together with the scale's relative brevity, extends its clinical relevance and utility beyond existing instruments.

This study suggests that CEQUEL has strong convergent validity. Higher CEQUEL scores were positively associated with home hospice enrollment, as well as length of inpatient hospice enrollment. Higher CEQUEL scores were negatively associated with bereaved caregiver regret and with psychological trauma symptoms. Convergence with these post-loss indicators suggests that GEQUEL measures aspects of the caregiver experience that are of critical import not only during the dying process but also in post-loss adjustment. Finally, positive associations between CEQUEL scores and patient-physician therapeutic alliance are consistent with previous research demonstrating that therapeutic alliance results in less aggressive, burdensome EOL care and improved patient mental health [1], [58]. Taken together, these findings are consistent with the broader literature and support CEQUEL's validity as a measure of perceived quality of EOL care.

A unique contribution of CEQUEL is its inclusion of suffering and prolongation of death as key indicators of caregiver-perceived quality of care, and this report found data suggesting the importance of both. Lower Prolongation and Suffering scores (i.e. higher levels of perceived prolongation and suffering), were positively associated with caregiver regret, fear and negative religious coping. This finding is significant in light of the association between negative religious coping and caregiver mental health and QOL outcomes [39]. Higher Prolongation scores were also negatively associated with trauma symptoms, whereas lower Suffering scores were negatively associated with DNR orders and length of inpatient hospice enrollment. These unique associations highlight the importance of assessing for caregiver perceptions of suffering and prolongation of death in terminal care. The fact that caregivers identified the poorest perceived quality of care within the three Suffering items further speaks to this domain's influence on caregiver wellbeing.
The present study suggests several directions for further study. CEQUEL's reliability and validity need to be confirmed in noncancer patient and caregiver samples, as this population may interpret quality of care at the EOL differently. While CwC1 recruitment sites included a VA hospital and two communitybased sites (Parkland and $\mathrm{NHOH}$ ) that accounted for 58\% of the total present sample, the study also included several academic medical centers that might be more inclined towards or capable of aggressive interventions, including trial participation. Interestingly, there was no clear relationship between care setting (communitybased vs. academic) and CEQUEL scores in the present sample, with mean CEQUEL scores as follows: Simmons, 24.5; Parkland, 24.1; DFCI, 24.1; MSKCC, 23.9; CT VA, 23.4; NHOH, 23.4; and Yale, 22.8. Hospice enrollment at time of death was higher among CwC1 participants (63\%) than for total US deaths (45\%) in 2011 [59], but the proportion of hospice patients dying at home was quite similar between $\mathrm{CwC1}(70 \%)$ and the US $(66 \%)$, as were deaths on inpatient hospice units (CwC1: 19\%, US: 26\%). Taken together, these data suggest $\mathrm{CwCl}$ data provided a fairly representative sampling of patients. Nevertheless, these results should be confirmed with more recent data.

Future iterations of CEQUEL might also include more straightforward language for some items, such as item 5 (see Appendix S1). There was one item that used relatively simpler language to address the same concern of adherence to patient wishes ("During the last week of life, to what extent were patient's wishes followed regarding a course of treatment that focused on extending life as much as possible even if it meant more pain and discomfort, or on a plan of care that focused on relieving pain and discomfort as much as possible even if it meant not living as long?") but this item could not be retained due to negative error variance. Further refinement of CEQUEL should strive for scale items that are psychometrically sound but also simply stated. Researchers have questioned the reliability of retrospective data collected via post-death interviews rather than during the dying process [6], [7]. However, assessing caregiver perceptions of EOL care in 'real time' is not only impractical (i.e. knowing when patients are dying and being able to make concurrent assessments), but also ethically questionable (e.g., it pulls vulnerable caregivers away from the bedside when they may feel that their exclusive focus should be on the patient). Furthermore, bereavement experts are familiar with the tendency of caregivers to recall their loved ones' final days in excruciating detail for months to years into bereavement. Future research will need to compare the reliability of caregiver reports taken in the first few months of bereavement compared to six months post-loss.

Finally, our finding that Catholic caregivers and those with no religious affiliation scored worse than other groups on CEQUEL merits further examination of potential reasons for this disparity. One clue may lie in the use of religious coping. Predictably, caregivers with no religious affiliation were significantly less likely to use positive religious coping than any other group. Catholic caregivers, however, also used significantly less positive religious coping than Baptists, Pentecostalists or those selecting "Other" as their faith affiliation (including Muslim but excluding Protestant or Jewish). Perhaps this relative lack of a positive and loving connection with a higher power acts as a detriment to positive coping in general. The way in which Catholics perceive or cope with care in the final week of life may also be affected by internal conflict with the Church's teachings on redemptive suffering, or the Church's tension around withholding or withdrawing lifesustaining treatments. Caregivers with no religious affiliation may be at a disadvantage relative to those who can rely on an extra layer of support via their religious community, or a religious 
framework that lends broader meaning to times of crisis and loss. Future studies should move beyond hypotheticals and strive for concrete data to help explain why religious faith, or lack thereof, influences caregiver's perceptions of the quality of care provided to their dying loved one.

This study's findings are notable from a research perspective, but their clinical implications for social workers and other healthcare providers are equally important. A low pre-loss CEQUEL score may prompt a caregiver-team meeting in which caregiver expectations about preventing a prolonged death or mitigating perceived suffering are weighed against what is achievable, and redirection of care or reframing of caregiver interpretations are pursued as necessary. Clinicians in day-to-day practice are likely to overlook some of the key questions addressed in CEQUEL, resulting in situations where caregivers either 'act out' or suffer silently without the team understanding why. CEQUEL helps to identify these underlying causes of distress and, to the extent that these issues are effectively addressed, may mitigate caregiver-team conflict or poor bereavement outcomes. Similarly, post-loss CEQUEL administration may facilitate bereavement adjustment by enabling clinicians to identify, reframe and process underlying sources of regret, trauma or other distress. Each CEQUEL factor represents a component of care that may leave caregivers feeling like the team should have done something differently, or that caregivers themselves have failed their loved ones. Associations between CEQUEL scores and caregiver regret, including regrets about their own role in the final week of life, highlight this potential. The literature on caregiver regret in bereavement is limited, but suggests that regret resolution leads to improved bereavement outcomes [60]. Minimizing caregiver regret is one way to reduce suffering in bereaved caregivers, and CEQUEL provides clinicians with one way to identify caregivers at risk for post-loss regret and other bereavement sequelae. Our findings that low CEQUEL scores, as well as perceived prolongation of death and suffering subscales, are associated with negative bereavement outcomes will likely be of general interest to those caring for the dying, but perhaps particularly to advocates

\section{References}

1. Zhang B, Nilsson ME, Prigerson HG (2012) Factors important to patients' quality of life at the end of life. Arch Intern Med 172: 1133-1142.

2. Steinhauser KE, Clipp EC, McNeilly M, Christakis NA, McIntyre LM, et al. (2000) In search of a good death: observations of patients, families, and providers. Ann Intern Med 132: 825-832.

3. Patrick DL, Engelberg RA, Curtis JR (2001) Evaluating the quality of dying and death. J Pain Symptom Manage 22: 717-726.

4. Tilden VP, Tolle S, Drach L, Hickman S (2002) Measurement of quality of care and quality of life at the end of life. Gerontologist 42: 71-80.

5. Addington-Hall J, McPherson C (2001) After death interviews with surrogates/ bereaved family members: some issues of validity. J Pain Symptom Manage 22: 784-790.

6. Fowler FJ, Coppola KM, Teno JM (1999) Methodological challenges for measuring quality of care at the end of life. J Pain Symptom Manage 17: 114 119

7. Hinton J (1996) How reliable are relatives' retrospective reports of terminal illness? Patients' and relatives' accounts compared. Soc Sci Med 43: 1229-1236.

8. Heyland DK, Dodek P, Rocker G, Groll D, Gafni A, et al. (2006) What matters most in end-of-life care: perceptions of seriously ill patients and their family members. CMAJ 174. Available: http://www.cmaj.ca/content/174/5/627.full. Accessed 2013 May 8.

9. Russ AJ, Kaufman SR (2005) Family perceptions of prognosis, silence, and the 'suddenness' of death. Cult Med Psychiatry 29: 103-123.

10. Teno JM, Clarridge BR, Casey V, Edgman-Levitan S, Fowler J (2004) Family perspectives on end-of-life care at the last place of care. JAMA 291: 88-93.

11. Teno JM, Casey VA, Welch LC, Edgman-Levitan S (2001) Patient-focused, family-centered end-of-life medical care: views of the guidelines and bereaved family members. J Pain Symptom Manage 22: 738-751.

12. Steinhauser KE, Christakis NA, Clipp EC, McNeilly M, McIntyre L, et al. (2000) Factors considered important at the end of life by patients, family, physicians, and other care providers. JAMA 284: 2476-2482. for physician aide in dying (PAD). CwC1 did not address PAD and it is not the intent of the present study to argue for or against it. Our findings may have implications for this debate, however, particularly in light of recent findings that patients pursuing PAD often do so out of concern for lost autonomy, dignity and functional status, and that bereaved family members of these patients feel more certain that their loved ones' wishes were honored, more prepared for and accepting of the death, and less regretful about the circumstances of death [61], [62].

The results of this study suggest that CEQUEL is a reliable and valid tool for assessing caregiver perceptions of the quality of EOL care provided to dying cancer patients. By including novel dimensions of suffering and prolongation of death, we have developed an assessment tool that more fully captures perceived deficiencies in EOL care. CEQUEL appears to identify important targets for clinical intervention that can improve EOL outcomes not only during terminal care but also in caregivers' subsequent bereavement.

\section{Supporting Information}

\section{Appendix S1 Garegiver Evaluation of Quality of End-of- Life Gare (GEQUEL).}

(DOCX)

\section{Acknowledgments}

We would like to thank Kathleen McInnis-Dittrich, MSW, Ph.D. (Boston College Graduate School of Social Work) for her ongoing mentorship with Mr. Higgins in completing his doctoral studies, and in particular her insights into the present report.

\section{Author Contributions}

Conceived and designed the experiments: PCH HGP. Performed the experiments: PCH. Analyzed the data: PCH HGP. Contributed reagents/ materials/analysis tools: PCH HGP. Wrote the paper: PCH HGP.

13. Steinhauser KE, Christakis NA, Clipp EC, McNeilly M, Grambow S, et al (2001) Preparing for the end of life: preferences of patients, families, physicians, and other care providers. J Pain Symptom Manage 22: 727-737.

14. Emanuel LL, Alpert HR, Baldwin DC, Emanuel EJ (2000) What terminally ill patients care about: towards a validated construct of patients' perspectives. J Palliat Med 3: 419-431.

15. Singer PA, Martin DK, Kelner M (1999) Quality end-of-life care: patients' perspectives. JAMA 281: 163-168.

16. Hales S, Zimmerman C, Rodin G (2010) The quality of dying and death: a systematic review of measures. Palliat Med 24: 127-144.

17. Steinhauser KE, Bosworth HB, Clipp EC, McNeilly M, Christakis NA, et al. (2002) Initial assessment of a new instrument to measure quality of life at the end of life. J Palliat Med 5: 829-841.

18. Curtis JR, Patrick DL, Engelberg RA, Norris K, Asp C, et al. (2002) A measure of the quality of dying and death: initial validation using after-death interviews with family members. J Pain Symptom Manage 24: 17-31.

19. Byock IR, Merriman MP (1998) Measuring quality of life for patients with terminal illness: the Missoula-VITAS quality of life index. Palliat Med 12: 231244.

20. Wright AA, Zhang B, Ray A, Mack JW, Trice E, et al. (2008) Associations between end-of-life discussions, patient mental health, medical care near death, and caregiver bereavement adjustment. JAMA 300: 1665-1673.

21. Wright AA, Mack JW, Kritek PA, Balboni TA, Massaro AF, et al. (2010) Influence of patients' preferences and treatment site on cancer patients' end-oflife care. Cancer 116: 4656-4663.

22. Gries CJ, Curtis JR, Wall RJ, Engelberg RA (2008) Family member satisfaction with end-of-life decision making in the ICU. Chest 133: 704-712.

23. Koop PM, Strang VR (2003) The bereavement experience following homebased family caregiving for persons with advanced cancer. Clin Nurs Res 12: $127-144$. 
24. Ott CH, Lueger RJ, Kelber ST, Prigerson HG (2007) Spousal bereavement in older adults: common, resilient, and chronic grief with defining characteristics. J Nerv Ment Dis 195: 332-341.

25. Houts PS, Lipton A, Harvey HA, Simmonds MA, Bartholomew MJ (1989) Predictors of grief among spouses of deceased cancer patients. J Psychosoc Oncol 7: 113-126.

26. McDonagh JR, Elliott TB, Engelberg RA, Treece PD, Shannon SE, et al. (2004) Family satisfaction with family conferences about end-of-life care in the intensive care unit: increased proportion of family speech is associated with increased satisfaction. Crit Care Med 32: 1484-1488.

27. Hanson LC, Danis M, Garrett J (1997) What is wrong with end-of-life care? Opinions of bereaved family members. J Am Geriatr Soc 45: 1339-1344.

28. Norton SA, Tilden VP, Tolle SW, Nelson CA, Talamantes Eggman S (2003) Life support withdrawal: communication and conflict. Am J Crit Care 12: 548555.

29. Wendler D, Rid A (2011) Systematic review: the effect on surrogates of making treatment decisions for others. Ann Intern Med 154: 336-346.

30. Barry LC, Kasl SV, Prigerson HG (2002) Psychiatric disorders among bereaved persons: the role of perceived circumstances of death and preparedness for death. Am J Geriatr Psychiatry 10: 447-457.

31. Hebert RS, Schulz R, Copeland V, Arnold RM (2008) What questions do family caregivers want to discuss with health care providers in order to prepare for the death of a loved one? An ethnographic study of caregivers of patients at end of life. J Palliat Med 11: 476-483.

32. Fried TR, Bradley EH, O'Leary J (2003) Prognosis communication in serious illness: perceptions of older patients, caregivers, and clinicians. J Am Geriatr Soc 51: 1398-1403.

33. Wright AA, Keating NL, Balboni TA, Matulonis UA, Block SD, et al. (2010) Place of death: correlations with quality of life of patients with cancer and predictors of bereaved caregivers' mental health. J Clin Oncol 28: 4457-4464.

34. Hudson PL, Trauer T, Graham S, Grande G, Ewing G, et al. (2010) A systematic review of instruments related to family caregivers of palliative care patients. Palliat Med 24: 656-668.

35. Teno JM, Claridge B, Casey V, Edgman-Levitan S, Fowler J (2001) Validation of Toolkit After-Death Bereaved Family Member Interview. J Pain Symptom Manage 22: 752-758.

36. Cherlin E, Fried T, Prigerson HG, Schulman-Green D, Johnson-Hurzeler R, et al. (2005) Communication between physicians and family caregivers about care at the end of life: when do discussions occur and what is said? J Palliat Med 8: $1176-1185$.

37. Emanuel LL, Alpert HR, Emanuel EE (2001) Concise screening questions for clinical assessments of terminal care: the needs near the end-of-life care screening tool. J Palliat Med 4: 465-474.

38. DeCoster J (2005) Scale construction notes, 2005. Available: http://www.stathelp.com/notes.html. Accessed 7 May 2013.

39. Pargament KI, Koenig HG, Perez LM (2000) The many methods of religious coping: development and initial validation of the RCOPE. J Clin Psychol 56: 519-543.

40. Pargament KI, Smith BW, Koenig HG, Perez L (1998) Patterns of positive and negative religious coping with major life stressors. J Sci Study Relig 37: 710-724.

41. Pearce MJ, Singer JL, Prigerson HG (2006) Religious coping among caregivers of terminally ill cancer patients: main effects and psychosocial mediators. J Health Psychol 11: 743-759.

42. Kris AE, Cherlin EJ, Prigerson H, Carlson MDA, Johnson-Hurzeler R, et al. (2006) Length of hospice enrollment and subsequent depression in family caregivers: 13-month follow-up study. Am J Geriatr Psychiatry 14: 264-269.

43. Azoulay E, Pochard F, Kentish-Barnes N, Chevret S, Aboab J, et al. (2005) Risk of post-traumatic stress symptoms in members of intensive care unit patients. Am J Respir Crit Care Med 171: 987-994.
44. Akiyama A, Numata K, Mikami H (2010) Importance of end-of-life support to minimize caregiver's regret during bereavement of the elderly for better subsequent adaptation to bereavement. Arch Gerontol Geriatr 50: 175-178.

45. Latham AE, Prigerson HG (2004) Suicidality and bereavement: complicated grief as psychiatric disorder presenting greatest risk for suicidality. Suicide Life Threat Behav 34: 350-362.

46. Prigerson HG, Horowitz MJ, Jacobs SC, Parkes CM, Aslan M, et al. (2009) Prolonged grief disorder: psychometric validation of criteria proposed for DSMV and ICD-11. PLoS Med 6. Available: http://www.plosmedicine.org/article/ info \%3Adoi\%2F10.1371\%2Fjournal.pmed.1000121. Accessed 2013 April 12.

47. Prigerson HG, Cherlin E, Chen JH, Kasl SV, Hurzeler R, et al. (2003) The Stressful Caregiving Adult Reactions to Experiences of Dying (SCARED) Scale: a measure for assessing caregiver exposure to distress in terminal care. Am J Geriatr Psychiatry 11: 309-319.

48. Beck AT, Weissman A, Lester D, Trexler L (1974) The measurement of pessimism: the Hopelessness Scale. J Consult Clin Psychol 42: 861-865.

49. First MB, Spitzer RL, Gibbon M, Williams JBW (1995) Structured Clinical Interview for the DSM-IV Axis I Disorders - Patient Edition (SCID-I/P) version 2.0. New York, NY: New York State Psychiatric Institute.

50. Williams JB, Gibbon M, First MB, Spitzer RL, Davies M, et al. (1992) The Structured Clinical Interview for DSM-III-R (SCID). II. Multisite test-retest reliability. Arch Gen Psychiatry 49: 630-636.

51. Muthén B, du Toit SHC, Spisic D (1997) Robust inference using weighted least squares and quadratic estimating equations in latent variable modeling with categorical and continuous outcomes. Available: http://pages.gseis.ucla.edu/ faculty/muthen/full_paper_list.htm. Accessed 2013 February 11.

52. Muthén LK (2011) Binary data and factor analysis. Available: http://www. statmodel.com/discussion/messages/8/50.html\#POST962. Accessed 2013 February 11.

53. Fabrigar LR, Wegener DT, MacCallum RC, Strahan EJ (1999) Evaluating the use of exploratory factor analysis in psychological research. Psychol Methods 4: 272-299.

54. Cattell RB (1966) The scree test for the number of factors. Multivar Behav Res 1: $245-276$

55. Hayton JC, Allen DG, Scarpello V (2004) Factor retention decisions in exploratory factor analysis: a tutorial on parallel analysis organizational research methods 7: 191-205.

56. Yu CY (2002) Evaluating cutoff criteria of model fit indices for latent variable models with binary and continuous outcomes. Available: http://www.statmodel. com/download/Yudissertation.pdf. Accessed 2013 May 8.

57. Cortina JM (1993) What is coefficient alpha? An examination of theory and applications. J Applied Psychology 78: 98-104.

58. Mack JW, Block SD, Nilsson M, Wright A, Trice E, et al. (2009) Measuring therapeutic alliance between oncologists and patients with advanced cancer: the Human Connection Scale. Cancer 115: 3302-3311.

59. National Hospice and Palliative Care Organization (2012) NHPCO Facts and Figures: Hospice Care in America, 2012 Edition. Available: http://www.nhpco. org/hospice-statistics-research-press-room/facts-hospice-and-palliative-care. Accessed 2013 March 20

60. Torges CM, Stewart AJ, Nolen-Hoeksema S (2008) Regret resolution, aging, and adapting to loss. Psychol Aging 23: 169-180.

61. Loggers ET, Starks H, Shannon-Dudley M, Back AL, Appelbaum FR, et al. (2013) Implementing a death with dignity program at a comprehensive cancer center. NEJM 368: 1417-1424.

62. Ganzini L, Goy ER, Dobscha SK, Prigerson HG (2009) Mental health outcomes of family members of Oregonians who request physician aid in dying. J Pain Symptom Manage 38: 807-815. 